\title{
Just Look at the Numbers: A Case Study on Quantification in Corporate Environmental Disclosures
}

\author{
Janne T. Järvinen ${ }^{1} \cdot$ Matias Laine $^{2}$ (D) $\cdot$ Timo Hyvönen $^{2} \cdot$ Hannele Kantola $^{1}(\mathbb{D}$
}

Received: 26 June 2018 / Accepted: 5 August 2020 / Published online: 14 August 2020

(c) The Author(s) 2020

\begin{abstract}
This paper sheds further light on the role of quantification in corporate environmental disclosures. Quantification is an inherently social practice, which has attracted a fair amount of academic interest in recent years. At the same time, in the field of social and environmental accounting there is a paucity of research on quantification or the role it plays for organisations, for organisational communication and in societies more broadly. Accordingly, in this paper, we will draw on a qualitative case study to discuss the potential implications that might arise from the use of quantified information in corporate environmental disclosures. Our case study illustrates the diverse effects of quantification suggested in the prior literature by placing them in the context of corporate environmental disclosures. We discuss how quantification implies fake precisionism and promotes commensuration of incomparables, thereby limiting the discussion to themes and questions preferred by company management. We maintain that quantification, while appearing to produce neutral and value-free information, has a substantive ethical dimension through how it implicates accountability relationships as well as the respective power relations between diverse stakeholders in societies.
\end{abstract}

Keywords Environmental disclosures · Quantification · Ethics of numbers · Case study

\section{Introduction}

Corporate sustainability and social responsibility have become everyday issues for most modern organisations. Despite this prominence, there are also vast contradictions: while business groups and corporations use all kinds of media to highlight their social responsibilities and various commitments to sustainability, there is also a constant flow of stories regarding the involvement of corporate entities in corruption scandals, modern slavery, human rights abuses,

Matias Laine

matias.laine@tuni.fi

Janne T. Järvinen

janne.t.jarvinen@oulu.fi

Timo Hyvönen

timo.hyvonen@tuni.fi

Hannele Kantola

hannele.kantola@oulu.fi

1 Faculty of Economics, Accounting \& Finance, Oulu Business School, University of Oulu, Oulu, Finland

2 Faculty of Management and Business, Tampere University, Tampere, Finland and political manoeuvres seeking to reduce environmental regulation and diminish natural sanctuaries. Clearly, the relationships between business, societies and nature are not straightforward (e.g. Bebbington et al. 2020; Folke et al. 2019).

Within this context, one prominent and swiftly evolving phenomenon is corporate sustainability reporting, the role and relevance of which in society remains debated (see e.g. Bebbington et al. 2014; Crane and Glozer 2016; Laine et al. 2020; Michelon et al. 2016; Saxton et al. 2019). Cho et al. (2015), for instance, split previous work in the field into two rough camps: those perceiving such disclosures as credible signals to the market about corporate activities and performance (e.g. Dhaliwal et al. 2012), and others considering the reports as little more than rhetorical devices used for impression management and as such to serve the corporations' private interests (e.g. Boiral 2013; Beelitz and MerklDavies 2012; Borgstedt et al. 2019). Obviously, such categorisations are by definition simplifications, and more diverse views can be found in the literature. Still, several authors have called for scholars to use a broader variety of theoretical approaches that could help us reach a more nuanced understanding of corporate sustainability disclosures, their 
use and subsequent impacts in societies (see, e.g. Cho et al. 2015; Michelon et al. 2016; O'Dwyer and Unerman 2016).

In this paper, we focus on the use of numbers and other types of quantified information in corporate environmental communication. Currently, quantified information is in many contexts considered to be superior to qualitative information (see Espeland and Sauder, 2016; Porter 1995, 1992). Quantified information seems more accurate, and it appears to allow comparisons both over time and across organisations, hence the use of such data in environmental issues is preferred and recommended by professional business networks, sustainability reporting frameworks and in the increasingly popular ESG indices and rankings, albeit sometimes with caveats concerning data quality (see A4S 2016). Similarly, in prior research on corporate environmental reporting, scholars have often used indices of data quality, in which quantified environmental information in general, and monetised information in particular, is considered to be of higher quality than qualitative information (Hooks and van Staden 2011; Aerts and Cormier 2009; Al-Tuwaijiri et al. 2004; Wiseman 1982). At the same time, it seems that in the field of social and environmental accounting there is a paucity of research on quantification or the role it potentially plays for organisations, for organisational communication and in societies more broadly.

In seeking to provide new insights to the discussion, we will draw on the sociology of quantification (e.g. Desrosieres 2001; Espeland 2016; Espeland and Sauder 2016; Mennicken and Espeland 2019) to illustrate the role numbers play in the process of communicating environmental information. Prior literature suggests that representing environmental actions as numbers is likely to have diverse effects. On the one hand, quantified environmental information may incur 'fake precisionism' (Power 2004), the comparison of incomparables (Espeland and Sauder 2016; Merry 2016) and rankings that normalise contemporary society's programmatic regime of evaluating environmental practices (Chelli and Gendron 2013). On the other hand, quantification can offer 'a rigorous method for democratising decisions and sharing power' (Espeland and Stevens 1998, p. 330) and is therefore useful when mobilised in incorporating the disparate values of various stakeholders in conflicts between different stakeholders (Mau 2019; Mehrpoya and Samiolo 2016). Still, when considering different stakeholder groups and their respective value positions it is pertinent to distinguish between numbers and the processes that lie beneath them. That is, if numbers are given without opening up the black box used to produce those figures, any potential for conversation between different groups and value positions becomes undermined (see Carlsson-Wall et al. 2016; Chenhall et al. 2013).

Accordingly, this paper aims at enhancing our understanding of the role quantification can play in corporate environmental disclosures, by discussing the potential social and ethical implications the use of quantification may have on an organisation's position in society, its relationships with stakeholders and the expected nature of information used therein. Thereby, we answer the call by Espeland and Stevens (2008) to investigate the ethics of numbers by discussing how the ethical aspects of quantification are embedded in communicating environmental information. Our findings highlight how the assumed general trustworthiness and objectivity carried by quantified information can be used in corporate environmental communication to establish boundaries for a discussion. Quantification can be used to promote commensuration of incomparables, which aids in creating ostensibly value-free settings that frame the conversation and limit it to particular viewpoints only. At the same time, quantitative information helps create impressions of expertise, thus implying that some actors are those who are knowledgeable of the subject matter, while simultaneously positioning some others on the periphery, implicitly presenting them as relying on beliefs, myths and other subjective considerations. By framing the conversation around quantified information, an organisation can limit the opportunities of weaker stakeholder groups to participate in a conversation, as those with limited resources are not necessarily able to come up with convincing numbers. Thereby, we argue that the use of quantified information has potential implications for accountability relationships as well as power relations between diverse stakeholders in given social settings (see Dillard and Vinnari 2019). As such, we maintain in this paper that the ethical dimension of quantification deserves closer consideration than it is generally granted both in social settings and in scholarly work.

Our discussion is based on a qualitative case study of a Finnish energy company, which uses peat as its primary raw material. Although peat has been considered an important element in Finnish energy production for decades, its use has been questioned in a wide-ranging social debate that focuses on the environmental impacts of peat production and combustion. Our case organisation is a major player in the industry and, as such, has been receiving increasing criticism from various citizen groups and NGOs with respect to its environmental policies and practices. The focus of our study is on the period 2010-2013, during which the debate over peat production escalated substantially. In the summer of 2011, in the midst of this social debate, the company was headed by a new top management team, who from the very beginning emphasised that they were going to improve the environmental record and reputation of the company. Accordingly, in this paper we discuss how the case company used various types of quantified information in its external environmental communication during the social debate. For this purpose, we draw on a rich qualitative dataset, including press releases, annual reports and stakeholder newsletters 
published by the case company, interviews with twenty-six employees of the case company, as well as media articles from leading Finnish newspapers and the business media.

From this point, the paper is organised as follows. The second section considers prior literature on the sociology of quantification. The third section discusses our data and method, while the fourth section contextualises the study and presents the case company. The penultimate section focuses on the findings, after which we discuss our findings and conclude the study in the final section.

\section{Accounting Figures and the Role of Quantification}

\section{Quantification in Contemporary Society}

Quantification, broadly defined as the production and communication of numbers, has always been a critical feature of modern society. In this section, we draw on the body of literature called the sociology of quantification, especially Porter (1992; 1995), Espeland and Stevens (1998; 2008), Espeland and Sauder (2016) and Mennicken and Espeland (2019), to illustrate the importance of the practice of quantification for communicating abstract but often contradictory ideas. Their arguments are informed by the thinking of Desrosiers, according to whom numbers, while representing reality, also intervene in people's interpretations about the reality they represent. For Espeland and Stevens (2008) quantification is the dominant mould for understanding other grammars of evaluation. A central point is to realise that quantifications used by organisations are social conventions, created rather than given, and are also reflexive in their potential to influence the object of measurement (Espeland 2016; Chiapello and Walter 2016). It is this tension that is the prominent feature of quantitative information. We speculate that perhaps the contradictory nature of numbers is key to allowing their dominance in an increasing number of fields of life.

Quantification involves first-order and second-order measurements. For instance, basic accounting represents a first-order measurement that quantifies economic transactions and makes them recordable and commensurable. Even such simplistic processes of quantification represent a purposeful action that relates to some broader agenda (monitoring the accumulation of profit, tax collection, choosing courses of action). Thus, while the seeming trustworthiness of accounting numbers as a first-order measurement is founded upon consistent and seemingly neutral practices, Desrosières' (2001) concept of metrological realism implies that the object of measurement, no matter how abstract or socially constructed an idea it may be, is nevertheless assumed to be as concrete as any real object. In fact, much of the research in accounting views the production of numbers as inherently political, that cannot be separated from wider projects of control, but should instead be viewed as a product of programmatic ambition (Rose and Miller 1992). For instance, Miller and O'Leary (2007) illustrate how discounted cash flow techniques (DCF), while quantifying projections about the future, are not just a matter of financial valuation, but inform much broader issues of managing and coordinating investments, and how a simple quantified measure, Moore's Law, can link investments, science and the economy at large.

In their seminal study, Burchell et al. (1980) argue that even simple accounting numbers should not be viewed as an objective description of 'reality' that impartially informs decision-making. Rather, accounting is a form of communication that can both promote and prevent dialogue; find support for arguments as well as justify decisions that have already been taken. Likewise, Arrington and Francis (1989, 1993) frame accounting as the act of giving economic accounts that has inherently moral underpinnings. Since accounting numbers are constructed, the 'truth' invested in them cannot be separated from the power of the speaker and resources s/he can draw upon.

Accounting-based quantifications also promote visibility and transparency in organisations. For instance, Miller and O'Leary $(1993,1994)$ illustrate how accounting numbers created a 'calculable space' that promoted a discourse of economic citizenship, which allowed the monitoring of different aspects of efficiency and quality. This way, quantification both enabled workers by tapping into their skills and potential, and at the same time made them subject to calculations concerning outsourcing and job reduction. In a similar fashion, Vaivio (1999) discusses calculable spaces in which consumers and customers are quantified and their profit generating potentials individualised and made visible.

For second-order measurements, i.e. 'measures on measures', the world consists of both producers and customers of quantified data, which in the realm of accounting would entail finance departments, auditors, financial analysts and credit rating agencies, all with their separate and distinctive agendas. Although not necessarily precise in themselves, they reproduce ideals of precision and accuracy connected to quantification. As second-order measures are normalised, they are frequently removed from their origins of production, and become systems of circulating quantified objects in a hyper-reality of calculation (Power 2004; Vollmer 2003).

A particularly powerful form of second-order quantification is the establishing of and reliance on various rankings and league tables, which has become a pervasive feature of contemporary society (Sauder and Espeland 2009). Desrosieres (2001) illustrates how such quantitative rankings are often originally intended as descriptive measures, but they nonetheless quickly become prescriptive (see Chelli and Gendron 2013). In fact, ratings and league tables, while 
making visible an organisation's competitive position, also address uncertainty by implicating what counts, what is noticed and what is not, and what goals ought to be maximised (Mennicken and Espeland 2019). At the same time, such new competition-oriented visibilities also introduce new uncertainties, anxiety and stress. Even then, people may exhibit emotional attachment to numbers that become symbols of belonging, identity and status. For instance, scholars are known to exhibit feelings of joy as their school rises in the rankings, and feel stress or even shame when the ranking drops (Espeland and Sauder 2016).

Such commensuration activities are often deeply embedded in organisational life and the social relations of its actors (Gerdin and Englund 2019). Notably, the increasing reliance on ratings and rankings is not in any way an unintended consequence of pervasive quantification. For instance, Chelli and Gendron (2013) illustrate how sustainability ratings, while promoting an ideology of numbers, ultimately lead to a regime that normalises the governance of socio-environmental performance. In fact, rankings seem especially useful in areas such as environmental reporting, where quantification is at least superficially voluntary as the regulatory power of state does not extend to the domain of reporting. In such regulatory capitalism (Braithwaite 2008), various NGOs can assume the role of mediators and interpreters of environmental rankings (Chelli and Gendron 2013), but which at the same time provides opportunities to contest the numbers (Didier 2018). Mau (2019, p. 173) asserts this as the 'paradoxical simultaneous status consolidation and status fluidity by rankings'.

All in all, studies of the sociology of quantification have so far concluded that various ratings and league tables that rest on multiple levels of aggregation, while being seductive (as they allow for easy comparison and ranking of organisations and their actors) also have the potential to lead to oversimplified interpretations and questionable commensuration of incomparable items. Critics remind us that such evaluations should be grounded in qualitative, locally-informed systems of knowledge production (Espeland and Sauder 2016; Merry 2016).

Espeland and Stevens (2008), according to their call for ethics of numbers, assert such ontological statements-reality being defined by measurability - as the first ethical implication quantification might entail. A further ethical implication relates to the idea that authority in numbers derives from their long-term association with rationality and objectivity. Specifically, numbers bear authority because of the sense of their accuracy and validity, their usefulness in solving problems, and how they link together actors with various interests in the numbers. In fact, Porter (1992) argues that quantification using numbers is generally intended to create trust, as for instance accounting numbers constitute a system of rules that is designed to block self-interested distortion.
However, trust in numbers is not a simple dichotomy of trust or distrust (Porter 1995). On the one hand, we tend to trust in numbers and vest them with real or imagined authority. However, on the other hand, we realise that the creation of systems of classification result in forced notions of similarity and commensurability, and that 'fake precisionism' characterises quantified measurement (Porter 1995).

\section{Decision-Making and Communication with Numbers}

Importantly, numbers are invested with value in how they inform decision-making as well as how they allow the organisation to communicate what has been decided, both aspects of which are implicated in ethical debates.

Quantified information has proven useful in directing and focusing the attention of actors while simultaneously appearing disinterested and neutral. This way, quantified objectives imply a direct link to decision-making (Borgstedt et al. 2019). Especially the knowledge concerning accounting is useful in legitimising new subject matter as well as the behind-the-scenes controversies associated with the application of accounting knowledge (Kaspersen and Johansen 2016; Potter 2005). Thus, 'numbers make a messy world seem easier to manage' (Espeland and Sauder 2016, p. 21). In this process, quantification forms a shared language (Espeland and Sauder 2016), where accounting plays a significant role (Porter 1992). As all numbers contain inherent preconceptions as to what is relevant, valuable or authoritative, decisions based on quantified reports disguise values invested in the numbers, setting methodologically controlled information against seemingly subjective evaluations (Espeland and Stevens 1998; Mau 2019).

However, as organisational goals can sometimes be fuzzy, unclear or outdated, decision-making and communication can rarely be fully consistent. In fact, a loose coupling between the numbers and the actions they represent may be an essential feature of quantified disclosures (Laine et al. 2017). Kadous et al. (2005) suggest that while accounting quantifications will usually enhance the credibility of business proposals, quantifications may also enhance the criticism of such proposals by allowing the decision makers to discuss small details. The relationship between the whole and its parts is especially problematic in second-order quantifications such as rankings by various indexes. This is because the process of reverse engineering, e.g. breaking down a quantified measure or an index to its components, inherently assumes salience of logical connections between measures and activity. Quantification thus has the potential to encourage decision makers to see logical connections that may not exist, and to have them focus on numbers rather than what the number is supposed to measure (Espeland 2016; Kadous et al. 2005).

In this process of quantification, information becomes condensed and easy to circulate, creating a means of 
communication we imagine to be universal. This way, information about how organisational goals have been achieved can also be disclosed and communicated to external users. According to Kaspersen and Johansen (2016), disclosures of quantified information have become known as a superior way of becoming at least superficially accountable, responsible and transparent. Also, the fact that such disclosures can be subjected to scrutiny and audited has become a permeating feature of modern society (Power 2004). According to Espeland and Stevens (2008), ethical implications of quantification become apparent in connecting numbers with accountabilities, to the point that 'we cannot understand the basic terms of justice if we do not understand quantification' (Espeland and Stevens 2008, p. 433). For instance, Gilles (2016) sets out an example of occupational physicians, who, being tired of having their recommendations ignored, set out on a project of quantification to increase the credibility of their efforts.

Especially when accounting technologies underpin information disclosure, quantified disclosures become difficult to challenge (Porter 1992). For instance, Vesty et al. (2015) illustrate the self-fulfilling and performative nature of reporting carbon emission figures. Similarly, Laine et al. (2017) investigate how environmental cost figures are only loosely connected to environmental actions and how producers of such numbers debate their meaningfulness, but nevertheless find accounting-based reporting worthwhile. With regard to environmental ratings, these are often collected by specialised agencies that compile and process information. In this way, society increases its own reflexivity through controlled observations (Chelli and Gendron 2013). Notably, many rankings, credit ratings or sustainability indexes do not require the consent of the object, as they are compiled using public data. While such public ratings are essentially devices whose job is to help to establish hierarchical categories, many unanswered questions remain that relate to how quantification is viewed by those who produce the numbers. In fact, classificatory practices embodied by rankings and ratings serve on the one hand to satisfy our comparative curiosity, and on the other to provide a point of reference, or a basis for decisions (Mau 2019).

As a conclusion, we contend that numbers can be successfully mobilised in ethical debates, investing formal reports with truth value while confining the arena of such debates to items that can be measured, calculated and ranked, and that this is especially the case with environmental information. We argue that such a narrow view of measurements serves companies' legitimation agendas well, and we deem it worthy to investigate how numbers are mobilised in the legitimation of activities that have an impact on the environment. At a more pragmatic level, we illustrate how ordinal scales of comparison are vital to communicating environmental goals, as they feed back on decision-making by implying what level of quantified scale is good enough to justify the claim that goals relating to environmental protection have been reached.

\section{Data and Research Method}

This qualitative case study is based on multiple qualitative datasets. Firstly, we conducted interviews with twenty-six employees from the case organisation, a Nordic energy company with an annual turnover exceeding 500 million euros ("Appendix 1"). This organisation has multiple business sectors; however, our investigation focuses on peat production, which is its core business. Interviews were conducted during a four-month period from late 2011 to early 2012. We proceeded within the organisation according to a data collection plan designed in advance. We began our data collection with the top management and continued down the organisational hierarchy. After interviewing key people from the organisation's main business areas and all of the employees involved in accounting and financial reporting on the group level, we focused our efforts on one business area, in which we interviewed employees from all organisational levels ("Appendix 2"). All subjects we approached agreed to be interviewed. All but one of the interviews were conducted on the case company's premises and lasted between $45 \mathrm{~min}$ and $2 \mathrm{~h}$. The interviews were semi-structured and loosely followed the interview guide we developed ("Appendix 3"). They were recorded and subsequently transcribed verbatim. At least two authors were present at each interview, with one of the authors taking part in all but two of the interviews.

We consciously sought to position ourselves as neutral in the public debate on peat production. Peat extraction is both politically regulated and publicly debated; thus, we approached it as a challenging business context, in which external factors had created substantial pressures and could transform the operating preconditions of the entire industry. Moreover, we acknowledged that the requirements and expectations set upon the industry have changed remarkably over the past decades. As peat usage has strong opponents in society, we considered it essential to communicate our neutral position to our interviewees. We were not there to find fault with the company, but rather, to learn about how the organisation and its employees navigated in the challenging business context and how they approached economic and environmental considerations in their decision-making.

In addition to the interviews, we collected a broad set of documents. While the main scope of this paper is limited to a four-year period between 2010 and 2013, we collected the case company's annual reports from 1980 onwards, as these disclosures assisted us in positioning the organisation's activities on an historical continuum and hence supplemented our interpretation. We also gathered the 
environmental reports, brochures and newsletters as well as all the press releases and stakeholder newsletters published by the organisation during our study period.

In order to enhance our understanding of how the company and its communications were received by the press, we collected data from various printed media outlets in Finland, including the leading national newspaper (Helsingin Sanomat), the leading business daily (Kauppalehti), the leading business weekly (Talouselämä), and the leading regional newspaper from the location of the case company's headquarters (Keskisuomalainen). Our media dataset consists of all the articles that either mention the case organisation by name or provide insights into peat, the main raw material used by the organisation.

Each of these datasets served our research purposes by shedding light on the role of numbers and other types of quantified information in environmental communication from a different perspective. The interviews aided in developing an understanding of how the employees within the organisation perceived the role and nature of environmental reporting. The analysed press releases demonstrated how the organisation used financial environmental information and other types of quantification in its communication during a period of sustained adverse publicity. The three decades of annual reports served as a supplementary dataset and gave us an historical perspective on how the organisation has used numbers and figures over the years. The environmental brochures provided us with examples of how quantification was used in environmental communication. Finally, the data collected from leading Finnish newspapers helped us understand how the disclosures and representations were received by and subsequently discussed in the press. We maintain that the use of several datasets was helpful to provide a more comprehensive understanding of the events and thereby increases the reliability of our interpretations.

For the analysis, each author independently read the transcribed interviews and made some preliminary interpretations. Likewise, the annual reports and the collected media datasets were read by all members of the research group, even though two group members had the main responsibility of analysing them. We subsequently shared our views and discussed individual interpretations. These interpretations continued to take shape, as we all independently recommenced our analyses to reinterpret the dataset based on each other's views. The findings presented here were formed on the basis of collective interpretation, which includes numerous iterations and reinterpretations.

\section{Case Study Setting}

Before moving on to discuss our empirical findings, we will in this section contextualise our study by providing some information regarding the role of peat production and combustion in Finland. We will also discuss our case organisation and the setting it was in when the new top management was appointed and began working towards enhancing the company's reputation. This will serve as a backdrop for our discussion on the role of quantification, and the different shapes and forms it takes in our case setting, which will be presented in the subsequent section.

\section{Peat Production in Finland}

This study is positioned in the midst of a prolonged social debate concerning the environmental impacts of peat extraction and the future this form of energy has in Finland (see Peterson 2014). Peat is a controversial source of energy, which is used for commercial energy production in Ireland and Finland, and to a lesser extent in some other countries (Schilstra 2001). Peat is in many ways parallel to coal and oil, and it is usually classified as a fossil fuel, even though peat technically re-accumulates through a very slow process extending over tens of thousands of years (see Tuohy et al. 2009; Schilstra 2001).

In Finland, peat is used in the generation of power for district heat and related electricity production, and the country is considered to be amongst the most advanced nations in terms of the research and technology used in peat production and combustion (Hakkila 2006). The importance of peat varies regionally: in about half of the Finnish regions peat is the most important fuel used in district heating, which has been commonly used since the 1970s to provide infrastructure services in the Finnish municipal energy sector (Finnish Energy Industries 2014; Åkerman and Peltola 2006).

The utilisation of peatlands in Finland is strictly regulated. All production sites are required to have an environmental permit, which defines for numerous details concerning both pre- and post-production operations. The mandatory requirements set out in the environmental permits, therefore, compel peat producers to make environmental investments. Moreover, before a permit is granted, the authorities examine the state and resilience of the watersheds located downstream of the proposed production sites.

Still, heated debates have taken place in Finland regarding the 'true' environmental impacts of peat production. In terms of climate change, peat producers and certain political parties argue that instead of being classified as a fossil fuel, peat should be seen as a slowly renewable biofuel, whereas numerous NGOs and other actors argue that the use of peat should be swiftly phased out. Peat production is also 
accused of destroying the natural habitats of species residing in swamps and bogs, while the producers on their behalf tout their engagement in natural reserves and restoration projects for a particular site once production at that site has ended.

It is evident that since the turn of the millennium public values with regard to peat extraction have been changing, and the public debate regarding peat production and combustion has steadily intensified. Both industrial peat producers and environmental NGOs have published websites to promote their views on peat production in general, its significance for Finnish society, and the possible consequences of peat production and combustion in relation to other energy sources (Lempinen 2013; Syrjämäki 2013). This has intertwined with evolving social awareness, as individual citizens and local groups have become increasingly irritated by the negative effects that peat extraction is perceived to have on local watersheds (see Peterson 2014). Polls have shown that until 2007, Finns consistently considered that the use of peat should be increased, but since then, the approval rate has dropped with the majority now maintaining that it should be diminished (Energiateollisuus 2017).

\section{The Case Company and Its New Mission: We are Better than Our Reputation}

This paper focuses on the period 2010-2013, during which the developing social context was posing substantial challenges for our case organisation, a major player in the Finnish peat industry, as its activities were under increasing scrutiny and political pressures were mounting.

As mentioned earlier, the top management of the organisation was changed completely during 2010-2011, and by summer 2011 the company had new CEO, CFO and CCO at the helm. Right from the start, the new top management made it clear that environmental issues would be a key question for the organisation, and they set out accordingly to improve the organisation's reputation. The majority owner of the company, the State of Finland, has not made official statements regarding the overhaul of the management group, and it therefore remains unclear whether the organisation's poor environmental reputation played a role. At the same time, it seems plausible to assume that the topic has been discussed, at least to some extent. This can be inferred from the way environmental issues were highlighted by the new CEO in the press release, which announced that he would take over in April 2011:

The case company is in my view better than its reputation, and my goal is to take the company a few metres further in a greener direction, not only in terms of our activities, but also in the public domain and on an emotional level.... I want to make all stakeholders proud of the possibilities forest energy and peat have. (CEO in case company's press release 9.9.2010) ${ }^{1}$

Our case organisation is well known in Finland, and its activities receive wide publicity on a regular basis. The appointment of its new CEO was not overlooked by the business press. An interview in the press with the CEO highlighted the harsh criticism to which the company had been subject in the previous winter (Talouselämä, 23/2011). The article made it clear that the CEO had come to the organisation with the aim of improving its environmental record and reputation. According to the interview, he was there 'to green the organisation, even though he thinks that the greenwashing of peat is a waste of energy'. (ibid.). At this stage, there was plenty of talk describing the company to be better than its reputation, but very little was offered in terms of tangible decisions or changes in operating practices. A similar message was also included in the press release that announced the appointment of the new $\mathrm{CCO}$ :

[The case company] is much greener and more responsible than its reputation suggests, but our targets are set way higher, also in these areas. (CCO in case company's press release 1.4.2011)

It is worth noting, however, that this was not the first time such attempts had been launched by the company. Preceding the period we focus on here, between 2008 and 2010, the case organisation had sought to improve its reputation with several large-scale advertisement campaigns. The claims the company had made regarding the nature of peat and the environmental impacts of peat extraction had received criticism, specifically from environmental NGOs. It had, on separate occasions, been accused of running a 'national diversion campaign' (Finnish Association for Nature Conservation [FANC] 19.12.2008), of 'distorting of peat information' (Chairman of FANC in Helsingin Sanomat 18.4.2010), and of using a massive advertisement campaign to 'greenwash peat' (Vihreä Lanka 14.10.2010; see Lempinen 2013). The case company's former CEO had denied any accusations concerning greenwashing and ascertained that 'peat promotion is based on facts, and any claims of disinformation are unfounded' (Former CEO in Helsingin Sanomat 20.4.2010). Nonetheless, it was from this basis that the new top management began its work.

In autumn 2011, the case organisation put a lot of effort into evaluating the business context, and it explored various scenarios with regard to the way society could develop in

\footnotetext{
${ }^{1}$ We indicate quotations from the interviews conducted for this paper with the interviewee's position only, whereas those drawn from the public domain mention also the original source (e.g. press release, annual report, newspaper). See "Appendix 1" for a list of our interviewees and the documentary sources.
} 
the future. Further, it began to develop an environmental strategy and sought to innovate new ways through which the organisation's reputation could be enhanced. Meanwhile, the negative press coverage continued, as one primetime news programme accused the organisation of destroying lakes in Finland. It also became evident that peat had become a contentious topic within the current Finnish government, as the Finnish Minister for the Environment stated that he 'would like the use of peat in energy production to end in 20 years' (Talouselämä 36/2011).

In the midst of this environmental criticism, the financial situation of the case company was also deteriorating rapidly. Consequently, the top management introduced a 'cost hunt' in which all the activities of the organisation were to be examined. In early December 2011, the organisation also issued a profit warning in which it emphasised the need to cut costs and improve efficiency. At this time, external environmental requirements and tightening regulations were set out as two reasons for the austerity measures. In a press release, the CEO was quoted as stating that "worse than expected financial developments in the sawn, pellet and energy wood business, a poor peat production season, tax increases for peat and indispensable additional environmental investments force [the company] to speed up actions aiming to improve cash flow and profitability, broadly defined' (Case company's press release 9.12.2011). These reasons were also mentioned in the stories published in the business press (e.g. Kauppalehti 10.12.2011).

\section{Bringing Numbers to the Fore: Religion or Calculations?}

As the organisation got going with implementing the environmental programme, it also began to actively communicate about its initiatives and highlight how it would as a result emerge as a different company. At the same time, in the organisation the key individuals were well aware that it could be hard to get the message across, both because there was in general some scepticism towards the organisation's self-laudatory environmental disclosures, but also in particular due to the case organisation's own past reputation.

The significance of environmental responsibility has changed really strongly, especially when it comes to peat. We have also received bad press, and I acknowledge that at least some part of that has been welldeserved. [Production Manager]

On this note, it is clear that the organisation's chief communication officer made deliberate choices in terms of how the message would be put across better.

I have got pretty far with my goals, if [the editor of Finland's second largest newspaper] sees our report and says that wow, they are talking about what they have not done. And perhaps writes a column asking whether something has actually changed. (...) So I somehow need to get our reports to their attention. (CCO)

Based on the empirical material, we concluded that different types of quantifications, comparative settings and numbers were to play a key role in the attempts to reposition the case organisation's environmental activities. In all this, there is also a strong overarching emphasis on how the organisation would be the expert in this area, and that it would be basing all its communication on facts. Simultaneously, this included positioning those challenging the organisation as outsiders, who would be advancing their cause ideologically or without having proper knowledge.

Religion or calculations? (...) Based on math classes, peat is good for Finland, and without a strong belief in something yet unknown, it would be hard to replace it. (CCO blog entry on company website, 2012)

It should be noted here that in earlier years there had also been numbers and quantified information in the organisation's disclosures. For instance, stand-alone CSR reports published during 2004-2007 followed the GRI guidelines and included physical metrics on, say, emissions, discharges and energy use. There is, however, a remarkable difference in where the numbers and quantified environmental information are reported and how they are presented. Instead of being offered as supplementary information in a separate report or on the website, we argue that the new top management brought quantified environmental information to the core of the organisation's communication, and relied upon it in seeking to reposition the organisation in the midst of the intensifying social debate.

We will now move on to discuss this in more detail in our empirical findings, in which we argue that in attempting to regain its societal legitimacy, the case organisation makes use of various forms of quantification in seeking to convince other social actors of the sincerity of its environmental programme. It is worth highlighting that we are not claiming that the organisation would not have changed its operational policies and actions, or that it would have merely been focusing on window-dressing in seeking to enhance how it is perceived in society. Instead, our interest is in using this case study to illustrate how quantification can be utilised in such a situation, and thereby to strengthen our collective knowledge of the role of quantification in social settings (see Mau 2019). 


\section{Findings: The Role of Quantification in Corporate Environmental Communication}

In this section we will present our empirical findings on how quantification featured in the case organisation's communication on environmental issues. We begin with some seemingly precise environmental accounting figures, continue by exploring how comparisons, commensuration and different scales are used, and thereafter look closer into how quantification and second-order measurements were in a key role when the organisation discusses its commitment to use best available techniques at its production sites. We finish this section with a discussion of how ethical aspects are an inherent feature of quantification.

\section{Accounting Figures as Environmental Information}

After several months of preparation, the top management finally launched the company's new environmental and responsibility programmes in mid-December 2011. At this stage, the role of the environmental investments began to be positioned differently. Whereas in the previous press releases they appeared to be problematic, as the 'indispensable environmental investments forced' the organisation to cut costs, the approach was now different and the CEO was quoted as follows:

We are currently going through major cost cuts, which force us to revise our general level of investments, but we will not allow this general cost hunt to hinder our responsibility programme, which has been prepared since the summer of 2011. (Case company's press release 16.12.2011)

The environmental issues were hence raised in importance from a nuisance to a key strategic question. The statement listed various measures through which it appears the organisation sought to convince the public that it was sincere in its measures to improve its future environmental performance. As much of the public criticism had targeted the pollution of watersheds downstream of the peat production sites, the core of the new environmental programme included a revised approach to water protection. In addition to making commitments regarding transparency and more intensive selfmonitoring, the organisation promised to invest in building more advanced water protection systems:

During the next three years we will significantly increase our investments in water protection. By the end of 2014 all production sites, which can have harmful impacts on the watersheds downstream, will be equipped with the best water treatment techniques.... This additional investment will cost approximately six million euros. On the whole, during the next three years we will invest 29 million euros to improve the efficiency of water protection facilities. Areas that cannot be equipped with [the best available techniques] and which cause undue impacts on the watersheds will be removed from production. (Case company's press release 16.12 .2011 )

From this point onwards, the organisation began to emphasise voluntary commitments, while failing to mention regulatory requirements. While tax increases for peat and the indispensable environmental investments had previously been blamed, by mid-February the CEO was presenting environmental responsibility as a 'very significant strategic change in the organisation's activities'. Furthermore:

Even though we are facing major financial challenges and we need to forego many growth investments, we have made the decision that we are not compromising our environmental investments. On the contrary. The published financial statement includes an additional provision of almost six million euros, which we will put towards the restoration of former production sites. (Case company's press release 17.2.2012)

The statement also reiterated the earlier total amount of environmental investments published: 'In December we announced a programme for the next three years according to which we will invest 30 million euros to improve the efficiency of water protection facilities'. (Case Company's press release 17.2.2012)

It becomes clear that after the organisation made public commitments regarding its new environmental strategy, the corporate communication also changed. We maintain that the key role given to financial environmental information is an example of how the organisation represents itself as being determined and committed to some future tasks. The sincerity of these organisational decisions is highlighted with the monetary figures, which appear to be reliable and exact, and hence more real than mere talk of being better than their reputation. Moreover, while the environmental issues related to peat production have appeared complicated, the emphasis placed on a clear monetary figure helps make them look manageable and shows how the organisation is in control (see Espeland and Sauder 2016; Kaspersen and Johansen 2016).

The use of monetary figures appears to have been attractive for the media, as the committed 29 million euros was featured regularly in the headlines. Right after the initial press release, a regional newspaper published in the town the organisation's head office is located in ran a story with the headline ' 30 million for the environment' (Keskisuomalainen 17.12.2011), referring to the scale of environmental investments the organisation mentioned in its statement. Other stories published elsewhere highlighted how 
the financially distressed organisation was willing to face financial sacrifices for the sake of the environment. Along with an investment of 30 million euros in water protection measures, it was reported that the organisation would close those production sites in which it could not make the necessary environmental investments; in other words, the building of sufficient water purification mechanisms. This decision was represented as a voluntary measure, which, according to the case company's CEO, will be made in spite of the financial consequences, such as '[losing] 30-40 million euros in revenue and a further seven million in downgraded profits' (Kauppalehti 20.2.2012).

It seems that exact figures of future environmental investments had great public appeal, as they were included in the leading media outlets' stories about the case organisation. Intriguingly, in early December 2011 these environmental investments were characterised as indispensable, and were presented as one of the reasons for the organisation's poor financial performance. Since then, the organisation has turned the role of these investments upside-down in its communications. These investments were thereafter portrayed as a sign of proactive environmental responsibility, emphasised in monetary terms. As pointed out by Porter (1995), Espeland and Sauder (2007) and Espeland and Stevens (2008), numbers are often associated with trustworthiness, rationality and authority. Disclosure of numbers constitutes an act of communication, the value of which is derived from reaching across distances that may be geographical as well as social or political. Simultaneously, disclosure of numbers, while improving decision-making and constraining discretion, works to limit the authority of other types of claims (Espeland and Stevens 1998). As such, we maintain that they served to strengthen the image of committed decisions made by the organisation. Furthermore, as time passed, additional emphasis was also placed on the voluntary nature of these investments, and any hints of regulatory requirements were removed from the organisation's communications:

[The CEO] highlights that [the company] invests huge amounts of money in water protection facilities. Moreover, it is doing so voluntarily, since it is according to the spirit of the times and the demands of society. (Case company's stakeholder newsletter 4/2012)

The function of the accounting numbers here seems to be related to signalling trust (Porter 1992) in the fact that the company is serious about environmental actions. At the same time, it narrows the debate to the measurable (Mennicken and Espeland 2019). The next section takes a closer look at these decisions, and discusses the organisation's actions in light of other documentary evidence as well as the views presented by the case organisation's employees.

\section{Comparison, Commensuration and Scales}

As has been noted above, our case organisation has been blamed for years for not taking care of its environmental duties as it should have. The peat production sites, spread out over vast geographical areas, are particularly relevant here. Being strictly regulated, each peat production site has to have an environmental permit, and there needs to be constant monitoring in place to collect information on the water outflows and discharges leaving the sites.

This is, however, not the case with all other industries, such as forestry and agriculture. One notable feature in the case organisation's environmental communication relates to the relative positioning of the organisation with other industrial sectors and activities.

We have specifically used resources in measuring and attempting to find out where all those discharges originate and how big a share of those does peat production really cause. It would naturally be important to understand the big picture, that is how much of those originate from agriculture, how much from forestry, and how much from peat. (Development Director)

On this note, it became evident that the organisation and its personnel were unhappy about how the peat industry was blamed for any incidents in which the water quality of a particular lake had worsened. The interviewees recalled various occasions on which a story published in the media had claimed that extensive discharges from some peat production site had caused the water of a previously clear lake to turn cloudy, although it was unclear whether there were any peat production sites located upstream of the lake in question. It was clear that in the case organisation there was a strong belief that the peat industry was undeservingly getting blamed for other industries' actions.

In reality the peat industry is not a major sinner here. For instance, the dykes forest companies dig in the swamplands as well as agriculture in general are tens of times, hundreds of times worse here. (Business Line Manager)

Such comparisons also featured prominently in the organisation's communication when it attempted to reposition itself in environmental matters during our research period. The environmental reports include diagrams emphasising how the peat industry causes less than $1 \%$ of the inflows to watersheds, with the rest originating from agriculture, forestry and other types of land use. Such calculations are uncertain, however, since while the peat industry has to monitor its production sites due to environmental permit requirements, the situation is different with the other industries. Still, these comparative scales are used in the public domain: 
If we cause over 1 per cent of this, we must be held responsible. But this must apply to everyone else as well. (CCO in a Letter to the Editor, Helsingin Sanomat, March 2012)

These figures, however, are strongly contested by environmental groups, with the Finnish Association for Nature Conservation, for instance, referring to the organisation's claims as the "great Finnish discharge hoax" (FANC 2012, 2014). The key point here is to acknowledge that producing any exact measures of water outflows over a vast geographical area is bound to be complex. Despite this, the organisation took a strong position in its communication, emphasising how they were unjustly getting the blame for problems that were in fact caused by others. For this purpose, estimated aggregate figures seemed to serve the purpose, as such numbers appear to be based on measurements and a steady methodology, thus providing more credibility for the claims. Still, when dealing with water discharges, it would be relevant to distinguish the aggregate figures from something taking place on the local level, as also noted by an interviewee:

The water discharges of the peat industry account for about 1-2 per cent of all discharges. So from that perspective it is not a major issue. However, when we get to the local level, you may have a trench or three flowing off each swamp, and as all these flow to the same lake nearby, the questions of water quality do come up differently. (Environmental Manager)

Here, the company made use of aggregated measures of water discharges that were compared with the often dissimilar discharges of other industries, creating a comparison of different entities according to a common metric (Espeland and Stevens 1998). This type of commensuration, while implicating what gets noticed and what is relevant (Mennicken and Espeland 2019), also establishes an implicit ranking of water polluters that highlights the relatively small scale of the case company's discharges. Other types of comparative scales are also evident in our empirical material. In communicating its environmental activities our case organisation often makes use of various metaphorical comparisons, which relate to the scale of things. These comparisons are often very mundane, which seemingly attempt to make things understandable or easier for the audience to comprehend. At the same time, however, they can also be seen as attempts to use comparative quantitative settings to portray a favourable representation of the organisation. One such area would be the organisation's environmental impacts, which are represented as miniscule through quantified metaphors.

The amount of sediments flowing within each litre of water leaving a peat production site weigh about the same as four flies would. (Company brochure, 2012)
Such a statement, further reinforced with visual imagery of four small flies, conveys the idea that the environmental impact would be negligible. Metaphorically, small flies are very mundane and familiar to all Finns, and are therefore something the reader can easily relate to and associate with something small. Still, it would require considerable expertise to know whether or not this type of sediment flow is of significance:

We have reported facts, like how much sediment, nitrogen or phosphorus there is. And probably then that grandma out there in the village will get lost, when I get beyond mere hectares and kilograms. We talk of grams per litre and all those things, so how would they know whether it is a lot or just a little. And then after all, when someone is standing in the lake next to her summer cottage, with brownish water between her toes, the impression she has is definitely of a certain kind. And here we are dealing with the most holy of things, it's your own summer place, and your feet are soaking in that brown stuff, so it is very easy to make a connection and ask what on earth is causing this. (Business Line Manager)

In addition to the environmental impacts, the organisation similarly uses quantitative scales to represent the relative significance of peat production in Finland. Again, the comparisons are set in such a way that they would be easy for most citizens to relate to.

Finland is using less than one per cent of all its peat resources ... peat will never be finished. (Chair of Board in a Letter to the Editor, Aamulehti, October 2013)

In Finland there is more than a hectare of swamp for each Finn. (CCO in a Letter to the Editor, Helsingin Sanomat, March 2012)

As was discussed above, it is not that these claims would not be based on facts and actual statistics. Finland is a sparsely populated and geographically large country, in which there are wide areas of unpopulated natural landscape. At the same time, what is omitted in making these comparisons is the fact that most of those swamps would not have any economic value in peat production. Moreover, the cost structure of peat production is such that the peat used for combustion at power plants cannot be economically brought in from very far. As such, most of the peat production sites are located in certain regions of Finland, implying that while the above comparisons of the scale of peat production are factually correct on the whole, on a regional and local level the situation can be substantially different. As was the case with the previously discussed type of quantification, the comparisons with other industries, in its communication the organisation here takes advantage of the opportunity to scale things in a way that represents its activities in a favourable light. 
With quantification and comparative scales, these types of metaphorical disclosures can prove powerful in conveying a particular impression. Here, quantification is something that is mobilised as ammunition in the conflict between the company and its stakeholders (Mehrpoya and Samiolo 2016). Key arguments relate to commensuration, what is argued as being comparable (Espeland and Stevens 1998; Gerdin and Englund 2019; Mennicken and Espeland 2019) and what issues are regarded as incomparable to trustworthy, preferably financial environmental information and therefore of lesser importance. The next section deals with a specific act of commensuration, namely establishing how big a percentage of the case company's production sites were using the best available environmental protection techniques.

\section{Best Available Techniques-By What Measure?}

As Mau (2019, p. 33) notes, quantification and numbers 'not only isolate information from its original context, but also place it in extensive comparative contexts'. Thus, when an abstract concept is quantified, it can also be compared, given that established metrics have, at least superficially, something in common (Espeland and Stevens 1998). While commensurability assumes that there must be at least one underlying quality that establishes a relation between compared objects, most often depending on a reference to money, social status etc., the absence of such unifying references can be avoided by setting a benchmark. On the surface, this resembles a second-order quantification: in our case a portfolio of different technologies in use is represented with a single ratio ranging from zero to one hundred. If this figure is reported to be close enough to a hundred, it also implicitly hints at a high ranking among comparable peers. In fact, such meta- measurement (Power 2004) is an important means for knowledge creation, allowing measures to be removed from their original context, while reproducing the ideals of precision and accuracy connected to quantification (Vollmer 2003; Mennicken and Espeland 2019).

Commensuration with a self-established benchmark took place when our case organisation pledged to use of best available techniques (BAT) in peat production. This was underscored in the initial launch of the environmental programme in late 2011 and was continuously highlighted thereafter. A closer look at BAT allows us to discuss how the selection of particular metrics and the use of comparative scales feature prominently in the case organisation's environmental communication.

In 2011 we published an ambitious environmental programme. We always operate in line with current regulations and environmental permitting requirements. We have now set our aims higher, however. In three years, we will be basing the water treatment at all our production sites on best available techniques. We will stop producing peat at sites where the best techniques cannot be applied. (CEO in Corporate Brochure, 2012) [The company's] new environmental responsibility becomes real through actions. The company will invest 30 million euros in more efficient water protection facilities by the end of 2014. With this amount, we will be able to equip all our production sites with the best possible water treatment facilities. Those production sites where more efficient water treatment facilities cannot be constructed will be removed from use. (Environmental Director in a Letter to the Editor, Keskisuomalainen, August 2012)

Importantly, while avoiding a direct comparison with other firms in absolute terms, the BAT measure nevertheless establishes implicit scales that an observer could use to establish a relative position of the case company in comparison to some unnamed others. Firstly, the very notion of best suggests that the organisation would do everything in its power to diminish the environmental impacts that its production is causing. Secondly, given the large number of production sites the organisation is associated with, the programme of taking such techniques to the sites provides an opportunity to represent the rapid progress in the implementation as a remarkable achievement. While both of these facts clearly hold water and can be seen as clear signs of improvement in the organisation's comparative environmental position, neither of them is as straightforward as they might seem in the first instance.

In the future, peat production will be responsible, which means that we will not only follow the law, but use the best available techniques and have the best possible attitude. (Chair of Board in a Letter to the Editor, Aamulehti, October 2013)

Evaluating something and establishing its worth always assumes classification and categorisation, i.e. establishing the group into which the valued items belong. By focusing on the ideas of best possible and best available, the BAT -measure creates an implicit classification system, where meaningful discussion takes place only within the category 'peat production'. As Power (2004, p. 767) notes, such categories are intended to ignore 'inessential' differences and reduce complexity. From this it follows that the type of activity the company is performing (environmental investments) should not be questioned, as it is only a matter of how they do it. Obviously, it should not be expected that an organisation would openly contemplate in its reporting that the entire industry will be wiped out in the notso-distant future. However, it is worth noting that the comparisons are not only about the entire industry, but also deal with decisions concerning peat production in particular swamps, watersheds and regions. Once opened for peat production, a 
site can be utilised for an extended period of time, and it can be helpful to justify the operations by referring to all actions being as good as possible.

As in any commensuration and classification process, where diverse issues are linked together by a common metric (Espeland and Stevens 1998), the key question here relates, however, to how one defines 'best available' or 'best possible' techniques, practices or solutions.

Speaking of this best available technology, which is demanded everywhere: It is mentioned in the regulatory standards, but there is really no such thing. It is totally impossible to define here, but it is still mentioned in the requirements. (...) And as it is not defined, it can turn into a grey area. Absolutely. And having more grey areas between the actors and the regulators is obviously not a positive thing. (CEO)

In the above, the potential negative outcomes the CEO refers to can be interpreted to relate to the various operational uncertainties which can arise in situations where the organisation does not know how the regulator is about to interpret the legislation, or that the requirements are implemented in different ways over time and in different places. As often noted, such regulatory uncertainty can easily cause higher costs and may for instance delay new investments, as organisations can be hesitant to use resources on initiatives or actions which can subsequently be hindered by a new regulatory interpretation.

At the same time, however, the flexibility of the definitions can also be used to the organisation's advantage, as evidently also happens in our case organisation. As noted above, in its communication the organisation seeks to represent the new environmental investments as its voluntary programme, although some of those are clearly mandated by regulatory demands.

According to its press releases and other public communications, the organisation seemingly wished to emphasise that the improvement of the water protection facilities was a novel initiative. Moreover, the key message was that these investments were a sign of a proactive environmental strategy, which would include substantial new actions. However, it is worth pointing out again that the organisation operates in a highly regulated industry in which the regulatory demands have become progressively stricter. Thus, much of the environmental costs and investments referred to in the communications were in fact mandatory for staying in business. However, in its own public statements regarding forthcoming environmental investments, such regulatory demands were not featured anywhere, even though the matter was clearly recognised within the organisation.

These environmental investments, well, they can of course also be voluntary, but usually we just have to do something in order to fulfil the environmental permit requirements in the future. (Business Controller)

Environmental expenditures show that the demands set out in environmental permits have become stricter.... There are all kinds of things which are constantly added to the requirements. (Environmental Manager)

If we have bad [environmental] results, and the current measures are not working well enough, we pretty much automatically know on the spot that renewing the environmental permit requires us to invest. That is a clear signal. (Production Manager)

All in all, establishing the BAT -measure implies that a category of measurement and a scale must be established. The established category or classification scheme pertains to peat production and limits other issues as irrelevant for discussion. Quantification is also used in this way to establish relevant topics of analysis (Power 2004), which in this case relate to how small the environmental impact of the case company's operations have, especially when compared to forestry and agriculture. As this information is quantified, it appears accurate and convincing (see Porter 1995), implying that such information has the potential to be used flexibly to advantage the organisation's cause. The assumptions underlying such comparisons or other forms of quantification are, however, left implicit, and as such the origins of the figures, scales or comparisons become black-boxed (see Mau 2019; Carlsson-Wall et al. 2016). Thus, quantification is an act of communication (Espeland and Stevens 2008) that reflects the values of the measurer, and it has therefore an ethical dimension. Our next section will discuss the implications of these issues in more detail.

\section{Ethics of Quantification}

As we have noted above, our case organisation used several forms of quantification in its attempts to enhance its reputation in environmental matters. The company had to identify a way in which quantification could connect to stakeholders. Here, we will concentrate on two main quantified measures, amount of environmental investments and the utilisation of best available techniques for water protection. As quantified information is known to be often associated with accuracy, reliability and trustworthiness, we maintain accordingly that the two main quantifications did not become part of the environmental communication by mere coincidence. They also helped to focus debates on issues that the case company felt favourable. We will next seek to take this discussion further through engaging with the ethical aspects of quantification (Espeland and Stevens 2008).

To begin with the financial environmental information, the pronounced 30 million euros' worth of forthcoming environmental investments seemed to work out well for the 
organisation. The case firm, especially its new $\mathrm{CCO}$, realised that the business media was interested in how much money was being spent on environmental investments, and decided to emphasise this in its communication. While connecting its message to external stakeholders, the news coverage also presented an opportunity to steer the public discussion to issues in which the company could be viewed in a positive light. As noted above, many newspaper stories that covered the organisation during the period investigated included a line on the 30 million euros' worth of forthcoming environmental investments touted by the organisation. It is debatable, however, whether there was actually anything novel here. The emphasis placed on these actions can also be viewed in a different light, once the 30 million euros is compared with the organisation's record over the previous 3 years.

The group's environmental investments were nine million euros ([compared to] nine million [in 2009]) and consisted mainly of water protection facilities at peat production sites. (Case company's Annual Report 2011, p. 32)

The group's environmental investments were 9.8 million euros. (Case company's Annual Report 2009, p. 41)

Based on the annual reports, it thus appears that the organisation had used a total of 28 million euros for environmental investments during the 3 years preceding the entrance of the new top management. Most of these investments were used to improve water protection facilities at peat production sitesthe same target the vaunted 30 million euros was to be used for. Hence, it appears that the 30 million euros was not a new phenomenon, but a continuation of the organisation's previous activities. Here, quantified disclosures were put to use in signalling rational behaviour and trust (Porter 1992, 1995). Nevertheless, these accounting-based figures appeared to be accurate and gave the impression that the company had made a major commitment to environmental protection (see Craig and Amernic 2004; Tinker and Neimark 1987):

Our company wanted to give the impression of a financially solid company, and succeeded. At the same time, it managed to give the impression of a financially solid company that is reluctant to invest in environmental protection. And now I would like to wake people up to the reality that it's the other way around; that is, we are not so financially solid [a company] but are still willing [to invest]. (CCO).

Peat has a pretty bleak reputation in Finland... so we have to have figures that show we have indeed put this many euros into these issues so that we try to show our stakeholders that we are not just passive and guilty of everything we are blamed for. (Financial Manager)

Such comments embody a key ethical aspect of quantification: the ontological stance of measurability, i.e. what is measured is 'real' (Desrosieres 2001) and that numbers, especially accounting numbers, should be trusted (Porter 1992). The reports are invested with a logic, according to which since the numbers show rising investment figures, environmental aspects have likely improved.

In contrast, in its internal communication, which is embodied in how the top management communicated the company strategy, the tone was slightly different. For instance, the CFO provided a more idealistic view of quantified reports, stating that instead of creating a gap between talk and action, numbers are also useful for getting things done.

I am at odds with the idea that we would produce reports because we would like to show the world how great we are. In my opinion, it is not the starting point. This means that reporting is a good tool for making things work inside the firm. (CFO)

Internally, the management seemed to highlight the reflexive nature of quantification (Espeland and Stevens 2008), where being subjected to measurements and giving quantified accounts drive organisational actions. Relating to this, the CFO continued:

My job is to make sure that our house is clean. And I can affect this by measuring it, I can come up with targets. So an environmental strategy cannot have vague statements which are not tied to relevant measures that have to be achieved in a specific time frame, and compared to measurements of where we are now...[...]... that is the only way. (CFO)

While the CCO of our case company juxtaposed the company's 'scientific' facts with environmentalists' mythical arguments, discussions with the $\mathrm{CEO}$ and the $\mathrm{CFO}$ hint at the reflexive nature of quantification: numbers are mobilised to create new realities. This is purposeful action that has profoundly ethical underpinnings (Espeland and Stevens 2008).

In addition to accounting numbers, the case company's communication also made use of the "best available techniques' (BAT)—concept. Being a concept where individual environmental protection techniques are ranked and then aggregated to a single measure, BAT displays the characteristics of a second-order quantification. Typically for such aggregate measure, the logical connections between individual technologies in use and the grand idea that the measure displays best possible efforts in environmental protection is at best tenuous. While reaching out to the stakeholders, the measure steers discussion away from environmental outcomes to discussion about resource inputs. It also encourages a view that there must be some kind of a causal link between investments in technology and environmental conditions (see Mau 2019; Espeland 2016; Espeland and Sauder 2007, for discussion on such insinuated causalities). 
In addition to exhibiting the disconnected logic of a second-order quantification, BAT measure is also an act of commensuration (Espeland and Stevens 1998). Here, different technologies are made comparable to each other, and together they form an index measure that can be put to a scale where the company can 'measure' how it performs against a self-defined benchmark, and potentially undefined other organisations, too. Essentially, our case organisation takes advantage of the possibility to define the rate and scale of comparison for its progress in adopting the BAT. In its environmental report, the organisation uses visuals to emphasise how it is going to reach a $100 \%$ accomplishment rate in adopting state-of-the-art techniques in a few years.

Moreover, in what we interpret as a move to steer the stakeholder discussions to topics deemed favourable by the firm, the BAT graph notes how after the same time, the organisation will no longer have any production sites with only 'baseline' (non-BAT) water treatment techniques in use. Still, it is also mentioned that in 2011 the organisation was using BAT at a $77 \%$ rate, while at the same time over $60 \%$ of its production sites were described as being at the 'baseline'. Here, mobilising a vague BAT concept and comparing it to an equally vague 'baseline' establishes a framework for comparing different positions. As noted by Mau (2019, p. 45 ), the purpose of such rankings is not merely to indicate whether one has performed well or consistently with recognised standards: what matters is being relatively, not absolutely, excellent. And often, as Mau (2019) points out, such comparisons are performed for a third party. Instead of being a struggle for excellence, reporting the percentage of best available techniques in use at the production sites is in reality a struggle for visibility, which is by no means a symbolic one, but one in which real financial resources are at stake.

As such, the loose definition of the best available techniques allows the organisation to define what the best available techniques are as well as what their rates of adoption are (compared to a baseline that they can come up with themselves). While resembling a second-order quantification, the use of BAT is really not about measurement; rather, it is an act of translating qualitative information into a numerical form. In the environmental report, this is followed by the (accounting) measurement of investment figures, but positioning these as voluntary investments rather than costs of staying in business. While the CEO acknowledges that these types of grey areas in the regulation can be challenging for an organisation, quantification can be mobilised in turning such uncertainty into an opportunity, as noted in the following by the CCO.

So an organisation goes and gets this kind of fuzzy BAT in all locations. I mean, not all sites are ideal locations, you just cannot create a biological wetland next to your production site, or there might be some buildings or someone else might own the land next to it, so you do what you can, but you go and get this kind of fuzzy BAT in all the locations. Thereafter the organisation, whatever its industry may be, gets a right to speak. (CCO)

Thus, quantified measures can be used to establish accountabilities and signal ethical obligations (Power 2004; Espeland and Stevens 2008), such as environmental investments. However, at least initially, some of the accounting personnel who had served the company for years appeared to be suspicious of the new emphasis on reporting brought about by the recently appointed managers. For instance, the group controller who had a long career in the company commented:

We simply need to wait for some time to see whether this is just talk or are we actually going to do something. (Group Controller)

Some of the interviewees were actually willing to question the need for quantified environmental reporting. For instance, a business controller noted that:

It seems to be more like a matter of conscience, they may be kind of buying themselves a clear conscience with this, to argue that we are monitoring these things and doing something. (Business Controller)

By discussing reports as buying a clear conscience, the business controller seems to hint that numbers may have qualities to which people may feel emotionally attached. In the literature an often cited example of this would be a rise or fall in rankings (Espeland and Sauder 2016). In our empirical material, this is illustrated by the CCO:

So people have a feeling that there is too much dirty water. If I produce an Excel sheet proving that their feeling is wrong ...[...]... If I tell them that 90 per cent of all the things are $\mathrm{OK}$ and the (environmental) report concentrates on everything we have done so far, the people will still concentrate on the 10 per cent. (CCO)

Numbers illustrating finance-related environmental actions seem to provoke similar reactions. However, while numbers are rarely enough to convince anyone to change their mind about issues to which they are emotionally attached, we nevertheless maintain that quantification is mobilised here as a powerful tool in seeking to navigate the organisation within mounting social pressures and financial challenges. In this quest, the seemingly exact figures of environmental investments and other types of quantified information served well to create an appearance of rationality and objectivity, thus increasing the trustworthiness of the decisions the organisation emphasised in presenting its forthcoming intentions.

All in all, the foregoing illustrates how the case company used different kinds of quantified information to connect to its stakeholders. Business media was given the investment figures it craved, while avoiding the discussion whether these 
figures represented a strategic choice or were a cost staying in business. The BAT -measure illustrated to all stakeholders in a simple and accessible way how advanced the water protection technologies utilised by the case company were compared to a self-established benchmark, implicitly implying that the outcomes of water protection could not have been any better. In its internal communication about implementation of strategic objectives, the top management emphasised reflexivity, i.e. that the measures are self-fulfilling objectives, where the company will eventually achieve what is being measured.

\section{Discussion}

This paper draws on a qualitative case study to understand the role of quantification in corporate environmental disclosures. By interpreting our data through prior literature on the sociology of quantification, we discuss the potential implications the use of quantification may have on an organisation's position in society, its relationships with stakeholders and the expected nature of information used therein. Our case study illustrates the diverse effects of quantification suggested in the prior literature by placing them in the context of corporate environmental disclosures. We discuss how, on the one hand, quantification is used to bring together various stakeholders with their disparate values (Mau 2019; Mehrpoya and Samiolo 2016), while, on the other hand, also limiting the discussion to themes and questions preferred by the company management. The issues the case company made efforts to communicate to outsiders were the quantity of investments and whether best available techniques for water protection were in use. We argue that the quantified information appeared to be precise and persuasive, as such figures seemed to show how the organisation strived to improve its environmental performance. Prior studies suggest that numbers are often viewed as representing a self-evident reality (see Desrosieres 2001), which the company here used to establish the authority of its message. Inside the company, the top management framed such quantified measures are realistic business objectives, stressing the reflexive nature of measurement.

In our case study setting, we recognise a repeating pattern of the situational use of quantification in the case company's environmental disclosures. This involved mobilising various types of quantification, such as comparative scales, commensuration and metaphorical comparisons. The organisation appears to draw on quantification to make strong claims or provide talking points about their performance. In this way, the power of numbers is employed to position the organisation as a trustworthy and transparent entity, which is providing accurate information about its actions. The quantification helps the organisation to steer any conversation about its environmental activities to particular topics and perspectives. Through quantification the organisation also gets to set the terms of the discussion, as it is presenting what should be measured and how. This is important, as in this geographically widespread industry there are many alternative ways to measure and evaluate the environmental performance. Through establishing a particular type of quantification as the 'true' and 'neutral' benchmark, the organisation gets to define its accountability to those topics and questions it would be most willing to discuss, narrowing the arena of such debates to items that can be measured and calculated (Mennicken and Espeland 2019). We contend this was especially suitable for making arguments to external stakeholders about environmental issues (Chelli and Gendron 2013; Mau 2019). The trustworthiness is further underscored by emphasising how the measurements would be conducted by a reliable and independent third party. Still, it is worth noting that despite an external company conducting the measurements, their parameters were nonetheless decided by the case organisation. That is, the company was able to set the frame of the conversation on specific types of quantified information (Mennicken and Espeland 2019).

For instance, by emphasising the rising environmental investment figures, the organisation gets framed as a proactive company voluntarily committing resources to environmental improvements, instead of being portrayed as a laggard that only puts the required environmental protection facilities in place when the authorities demand them. We have pointed out how the environmental investment figures regularly appeared on the pages of newspapers, and further, that the figures represented the organisation in a positive way, as the media's portrayal made the organisation's commitment to its decisions seem sincere and effective. Quantified environmental cost information relayed the image of rationality and invested the company's actions with trustworthiness and legitimacy (Porter 1992, 1995).

Despite its obvious usefulness for firms, the power of quantification does not come without related potential ethical questions and implications (Espeland and Stevens 2008). The numbers and quantified information facilitate particular ontologies, suggest specific rationalities and imply certain accountabilities. In the economic context, environmental issues are always value-laden, as they imply a need to take into account different points of view, to settle and balance different value positions, and eventually to decide between potentially incommensurable and incomparable alternatives (see Boltanski and Thevenot 2006). In our case company, quantification helped the top management to steer the conversation of environmental performance towards issues it considered important, such as physical measures of water discharges, thereby avoiding questions related to environmental values requiring ethical judgements. The company mobilised quantification, which implies measurability, preciseness and objectivity, and hence offers the potential to represent one's own position as valuefree: just look at the numbers. There is no need to make value judgements, since the metrics are presented as neutral and 
trustworthy (Porter 1995; Desrosières 2001). Quantification simplifies the setting, narrows the frame and allows us to stay in the comfort zone, in which decisions can be made by comparing apparently commensurate and balanced information of equal stature. However, choices regarding how the numbers are produced, how they are distributed, how they are applied, and how they are made use of all have consequences. Here, the ethical dimension of such choices may get brushed aside: any selection of criteria, scale of evaluation or type of measurement involves value judgements and ethical implications (Espeland and Stevens 2008; Mau 2019).

This leads us to consider the implications that quantification has on accountability. It has been noted that accountability relations are not something set in stone; instead, these become shaped in social structures and interactions between various actors (see Dillard and Vinnari 2019). That is, not only are accountability relationships fluid in terms of who an organisation would primarily be accountable to, but also in regard to how this accountability should be discharged. We maintain that as quantification facilitates an organisation to set the tone of the discussion to consider particular topics, questions and metrics, it also has implications for whom the organisation is considered to be accountable to as well as how this relationship is shaped (see Cooper and Owen 2007). Does the organisation have power over which metrics become the 'true' and 'neutral' (Desrosieres 2001; Porter 1992) measures that are looked at when the discharging of accountability is considered, or does the organisation have to adjust substantively to the demands set upon it from the outside? In other words, we maintain that quantification, while again appearing to produce neutral and value-free information, has a substantive ethical dimension through how it implicates accountability relationships as well as the respective relations of power in those relationships (Espeland and Stevens 2008).

Using quantified information appears exact and draws on the truth value numbers have in societies. Thereby it also sets a higher bar for others seeking to contest the information provided: a stakeholder challenging quantified information with mere qualitative statements can be countered with a request to come up with numbers and exact information, or otherwise risk being categorised as someone relying on mere belief statements or religion (see Mau 2019). This could potentially lead to further marginalising of weaker stakeholder groups, who do not possess the resources and knowledge to produce figures. A powerful organisation could arguably appear as highly accountable and transparent by releasing regular sets of quantified environmental information, no matter whether those numbers would be very relevant or useful for anyone (see Dillard and Vinnari 2019; Porter 1992). Accountants have long known that information is power-and even more so when one gets to define which information is being used and how it is put together (Burchell et al. 1980). With such power comes also substantial ethical implications. The figures are not facts, but social conventions. Numbers are not neutral and value-free, but have implications on power and accountabilities, as some actors are prioritised and others considered peripheral (see Arrington and Francis 1993). Further research is needed to consider these questions in more detail.

The use of quantification in environmental communication also has significant social implications. There is a tendency by major actors in the area of sustainability accounting and reporting, such as the Big 4 accountancy firms, the Capitals Coalition, the Sustainability Accounting Standards Board and the A4S network, to promote the use of commensuration in their publications and recommendations considering sustainability accounting and reporting (see A4S Network 2016; Cooper and Senkl 2016). Granted, these often come with caveats concerning data quality and potential limitations, but the underlying tone contains a positive vibe towards the potential of commensuration and the monetisation of environmental issues, as this is argued to enhance the possibilities of organisations to take social and environmental issues into account alongside economic and financial considerations. Given the power of numbers and the various positive qualities associated with them, we maintain that it is nonetheless worth asking whether such a choice steers us away from some challenging ethical questions. To give an example, given how numbers and metrics can be reflexive in their potential to influence the object of measurement (Mennicken and Espeland 2019), we may for instance seek to improve particular numbers of one's environmental performance, even though this might at the same time be counter-productive for sustainability more broadly.

Likewise, second-order quantifications such as ratings and rankings have proven to be highly powerful and persuasive in the realm of organisations and sustainability. Rating schemes, be that the CDP's A-list, Global Knights Top 100 Most Sustainable Companies or the ESG scores of Thomson Reuters, are highly visible and carry considerable value as tokens symbolising excellence needed in societies' transformation towards less unsustainable practices (see Vollmer 2003; Chelli and Gendron 2013). A high score on such a list implies that a particular organisation is worth supporting. Yet, as has been pointed out (Porter 1995; Espeland and Sauder 2016), such scores are inherently simplifications, which commensurate a messy reality into simple, seemingly precise numbers, which we can readily compare and the development of which we can follow over time. With sustainability ratings and scores it is also worth noting that these second-order quantifications, which ostensibly measure organisational activities and performance, are often based on information organisations have reported themselves (Cho et al. 2012), including first-order quantifications, which in themselves may already be loosely coupled from organisational action (Laine et al. 2017; Boiral et al. 2019). Again, while appearing accurate, the metrics can be outright 
meaningless, but this does not necessarily diminish their visibility or limit the power such numbers carry, As such, we would expect more discussion concerning the ethical, social and political dimensions associated with the numbers and metrics used in sustainability disclosure frameworks, such as GRI and SASB (see Laine et al. 2020).

Finally, we maintain that our study has shown the value of using multiple data sources in research that seeks to understand organisational behaviour related to environmental disclosures. Despite acknowledging that our findings can neither be generalised nor directly applied in other contexts, we maintain that case studies can provide valuable insights by offering thick descriptions of complex organisational practices (see Gendron 2009; Bédard and Gendron 2004). Accordingly, drawing on our analysis of multiple datasets, we maintain that our findings contribute to the literature concerning the ambiguous nature and role of quantified financial and nonfinancial information in organisational settings. Therefore, we hope that future studies will make use of data sources beyond the published corporate disclosures in an attempt to shed light on these complex organisational practices.

Acknowledgements Earlier versions of this paper have been presented at the Nordic Accounting Conference, Copenhagen, Denmark, November 2018, the 37th EAA annual congress, Tallinn, Estonia, May 2014, the 2nd CSEAR France conference, Montpellier, France, May 2013, and at research seminars at the Universidad de Pablo de Olavide de Seville, University of Turku, Universidad de Burgos, University of Tampere, University of Central Florida and Bucharest University of Economic Studies. We are grateful for the comments we have received in those sessions. The usual caveats apply.

Funding We wish to acknowledge financial support received for this study from the Academy of Finland and the Finnish Foundation for Economic Education.

\section{Compliance with Ethical Standards}

Conflict of interest The authors declare that they have no conflicts of interest.

Ethical Approval All procedures performed in studies involving human participants were in accordance with the ethical standards of the institutional and/or national research committee and with the 1964 Helsinki Declaration and its later amendments or comparable ethical standards.

Informed Consent Informed consent was obtained from all individual participants included in the study.

Open Access This article is licensed under a Creative Commons Attribution 4.0 International License, which permits use, sharing, adaptation, distribution and reproduction in any medium or format, as long as you give appropriate credit to the original author(s) and the source, provide a link to the Creative Commons licence, and indicate if changes were made. The images or other third party material in this article are included in the article's Creative Commons licence, unless indicated otherwise in a credit line to the material. If material is not included in the article's Creative Commons licence and your intended use is not permitted by statutory regulation or exceeds the permitted use, you will need to obtain permission directly from the copyright holder. To view a copy of this licence, visit http://creativecommons.org/licenses/by/4.0/.

\section{Appendix 1: List of interviews and other data}

\begin{tabular}{|c|c|c|c|c|c|c|}
\hline & \multirow[t]{2}{*}{ Position } & \multirow[t]{2}{*}{ Duration } & \multicolumn{4}{|c|}{ Authors present } \\
\hline & & & A & $\mathrm{B}$ & $\mathrm{C}$ & $\mathrm{D}$ \\
\hline 1 & $\mathrm{CEO}$ & $2 \mathrm{~h}$ & $X$ & $\mathrm{X}$ & $\mathrm{X}$ & $\mathrm{X}$ \\
\hline 2 & Environmental Director/Group & $2 \mathrm{~h}$ & $X$ & $X$ & $\mathrm{X}$ & $\mathrm{X}$ \\
\hline 3 & Environmental Manager/Group & $2 \mathrm{~h}$ & $X$ & $X$ & $X$ & $\mathrm{X}$ \\
\hline 4 & $\mathrm{CFO}$ & $1 \mathrm{~h}$ & $X$ & $X$ & & \\
\hline 5 & Business Controller & $45 \min$ & & $\mathrm{X}$ & $\mathrm{X}$ & \\
\hline 6 & Financial Manager & $1 \mathrm{~h}$ & & $\mathrm{X}$ & $\mathrm{X}$ & \\
\hline 7 & Chief of Accounting & $45 \mathrm{~min}$ & & $X$ & $\mathrm{X}$ & \\
\hline 8 & Group Controller & $1 \mathrm{~h}$ & & $\mathrm{X}$ & $\mathrm{X}$ & \\
\hline 9 & Project Manager/Finances & $1 \mathrm{~h}$ & & $X$ & & $\mathrm{X}$ \\
\hline 10 & Production Director/Group & $1 \mathrm{~h}$ & & $X$ & & $\mathrm{X}$ \\
\hline 11 & $\mathrm{CCO}$ & $1 \mathrm{~h} 15 \mathrm{~m}$ & $\mathrm{X}$ & $\mathrm{X}$ & & \\
\hline 12 & Regional Director/Region A & $1 \mathrm{~h} 15 \mathrm{~m}$ & & $\mathrm{X}$ & & $\mathrm{X}$ \\
\hline 13 & Group Controller & $1 \mathrm{~h} 15 \mathrm{~m}$ & & $\mathrm{X}$ & & $\mathrm{X}$ \\
\hline 14 & $\begin{array}{l}\text { Production and Delivery Officer/ } \\
\text { Reg A }\end{array}$ & $45 \min$ & & $X$ & & $\mathrm{X}$ \\
\hline 15 & Environmental Officer/Region A & $45 \min$ & & $\mathrm{X}$ & & $\mathrm{X}$ \\
\hline 16 & Production Manager/Peat & $1 \mathrm{~h}$ & & $X$ & $X$ & \\
\hline 17 & Regional Manager/Region B & $1 \mathrm{~h}$ & & $\mathrm{X}$ & $\mathrm{X}$ & \\
\hline 18 & Project Officer/Region A & $1 \mathrm{~h}$ & $X$ & & & $\mathrm{X}$ \\
\hline 19 & Subcontracting Officer/Region A & $1 \mathrm{~h}$ & $X$ & & & $\mathrm{X}$ \\
\hline 20 & Development Manager & $1 \mathrm{~h}$ & & $\mathrm{X}$ & $\mathrm{X}$ & \\
\hline 21 & Regional Director/Region B & $1 \mathrm{~h}$ & & $X$ & $X$ & \\
\hline 22 & Quality Manager & $1 \mathrm{~h}$ & $X$ & $\mathrm{X}$ & & \\
\hline 23 & Environmental Manager/Peat & $45 \min$ & $\mathrm{X}$ & $\mathrm{X}$ & & \\
\hline 24 & Human Resource Director & $1 \mathrm{~h}$ & & $\mathrm{X}$ & & $\mathrm{X}$ \\
\hline 3 & Environmental Manager/Group & $1 \mathrm{~h}$ & & $\mathrm{X}$ & & $\mathrm{X}$ \\
\hline 25 & Business Area Director & $45 \min$ & & $\mathrm{X}$ & & $\mathrm{X}$ \\
\hline 26 & $\begin{array}{l}\text { Business Controller/Risk Man- } \\
\text { agement }\end{array}$ & $1 \mathrm{~h}$ & & $\mathrm{X}$ & & \\
\hline
\end{tabular}

Material published by the case company:

- Annual reports 1980-2013; CSR reports 2004-2007; press releases 2010-2013; website, blogposts and other material 2010-2013.

Media data-Articles referring to case company or peat from the following:

- Helsingin Sanomat (leading Finnish daily newspaper) 2010-2013 
- Kauppalehti (leading Finnish business daily) 2010-2013

- Talouselämä (leading Finnish business weekly) 20102013

- Keskisuomalainen (regional newspaper) 2010-2013
Appendix 2: Data collection plan for the study and the case organisation's structure
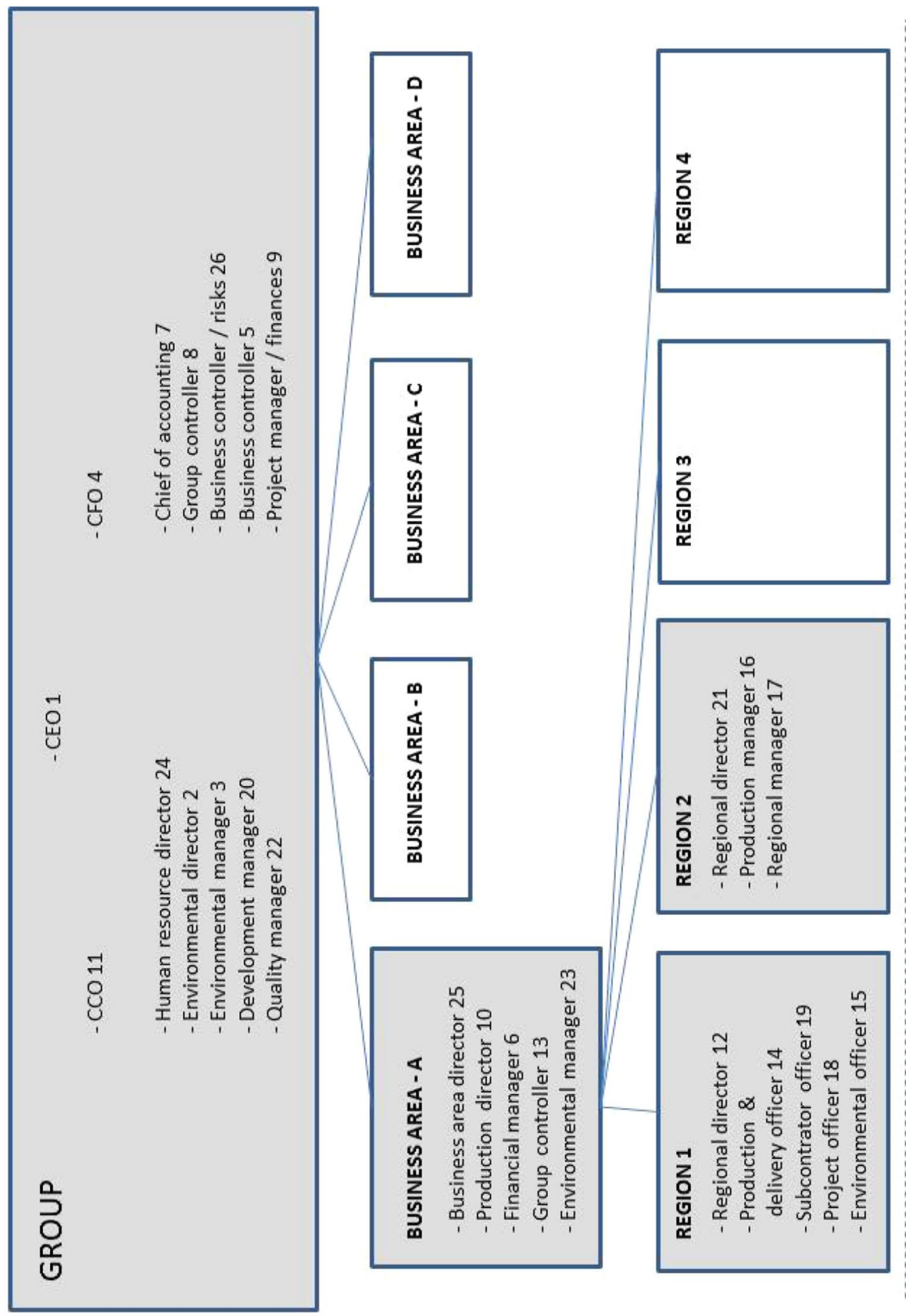

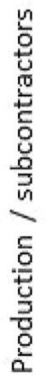

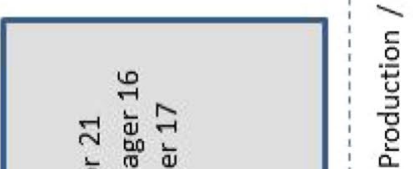

- Shaded areas within the organisation were targets of research

- Interviewee numbers refer to the order in which interviews were conducted 


\section{Appendix 3: Interview Guide-Instructive Themes for the Interviews}

Interviewee's background:

- Formal education and history within the organisation (how long, which positions, etc.)

How do environmental issues and corporate social responsibility feature within the organisation?

- In relation to the general aims of the activities?

- How are they visible in everyday work and in decision-making in general?

- Has this changed during the time you have worked for the company? How?

Your company has published environmental, and later on, corporate social responsibility reports from the late 1990s and onwards. In your view, what is the role of this voluntary reporting for your company?

- How do you make use of the reports within the organisation?

- (Does anyone read them?)

- (Your feeling of the company more broadly? Do you read them yourself?

- How do the employees view the reporting and its role within the organisation?

- Has this changed over the years? How?

- What role do the reports have in decision-making?

- (Do they influence decision-making?)

○ Why do you actually report on social responsibility and environmental issues?

- To whom do you report?

- (Do these groups make use of the reports?)

Could you tell us about the indicators that your organisation uses in regard to environmental and corporate social responsibility?

- How are these indicators used within everyday work and decision-making?

- How are they used in relation to financial indicators?

- How are they used in relation to investment decisions?

- What is the role in subcontracting and subcontracting agreements?

- Do you have explicit targets?

$\circ$ How are these set?

- How is the follow-up organised?

- In your view, how have these things changed during your time in the company?

How do you see the relationship between financial aims and environmental matters?

- Which issues primarily guide decision-making and activities within the company?

- How has this changed during your time with the company? 


\section{References}

Accounting for Sustainability [A4S]. (2016). Natural and social capital accounting. An introduction for finance teams.

Aerts, W., \& Cormier, D. (2009). Media legitimacy and corporate environmental communication. Accounting, Organizations and Society, 34(1), 1-27.

Åkerman, M., \& Peltola, T. (2006). Constituting the space for decision making - Conflicting calculations in a dispute over fuel choice at a local heating plant. Geoforum, 37(5), 779-789.

Al-Tuwaijiri, S. A., Christensen, T. E., \& Hughes, K. E. (2004). The relations among environmental disclosure, environmental performance, and economic performance: A simultaneous equations approach. Accounting, Organizations and Society, 29(5-6), 447-471.

Arrington, C. E., \& Francis, J. R. (1989). Letting the chat out of the bag: Deconstruction, privilege and accounting research. Accounting, Organizations and Society, 18(2-3), 107-124.

Arrington, C. E., \& Francis, J. R. (1993). Giving economic accounts: Accounting as cultural practice. Accounting, Organizations and Society, 14(1-2), 1-28.

Bebbington, J., Österblom, H., Crona, B., Jouffray, J.-B., Larrinaga, C., Russell, S., et al. (2020). Accounting and accountability in the Anthropocene. Accounting, Auditing \& Accountability Journal, 33(1), 152-177.

Bebbington, J., Unerman, J., \& O’Dwyer, B. (2014). Sustainability accounting and accountability. Abingdon: Routledge.

Bédard, J., \& Gendron, Y. (2004). Qualitative research on accounting: Some thoughts on what occurs behind the scene. In C. HumphreyM \& B. Lee (Eds.), The real life guide to accounting research. A behind-the-scenes view of using qualitative research methods. Oxford: Elsevier.

Beelitz, A., \& Merkl-Davies, D. (2012). Using discourse to restore organisational legitimacy: 'CEO-speak' after an Incident in a German Nuclear Power Plant. Journal of Business Ethics, 108, 101-120.

Boiral, O. (2013). "Sustainability reports as simulacra? An external account of A and A+ GRI reports. Accounting, Auditing and Accountability Journal., 26(7), 1036-1071.

Boiral, O., Heras-Saizarbitoria, I., \& Brotherton, M.-C. (2019). Assessing and improving the quality of sustainability reports: The auditors' perspective. Journal of Business Ethics, 155, 703-721.

Boltanski, L., \& Thevenot, L. (2006). On justification. Economies of worth. Princeton, NJ: Princeton University Press.

Borgstedt, P., Nienaber, A.-M., Liesenkötter, B., \& Schewe, G. (2019). Legitimacy strategies in corporate environmental reporting: A longitudinal analysis of German DAX companies' disclosed objectives. Journal of Business Ethics, 158(1), 177-200.

Braithwaite, J. (2008). Regulatory capitalism: How it works, ideas for making it work better. Cheltenham: Edward Elgar.

Burchell, S., Clubb, C., Hopwood, A., Hughes, J., \& Nahapiet, J. (1980). The roles of accounting in organizations and society. Accounting, Organizations and Society, 5(1), 5-27.

Carlsson-Wall, M., Kraus, K., \& Messner, M. (2016). Performance measurement systems and the enactment of different institutional logics: Insights from a football organization. Management Accounting Research, 32, 45-61.

Chelli, M., \& Gendron, Y. (2013). Sustainability ratings and disciplinary power of the ideology of numbers. Journal of Business Ethics, 112, 187-203.

Chenhall, R. H., Hall, M., \& Smith, D. (2013). Performance measurement, modes of evaluation and the development of compromising accounts. Accounting, Organizations and Society, 38(4), 268-287.
Chiapello, E., \& Walter, C. (2016). The three ages of financial quantification: A conventionalist approach to the financiers' metrology. Historical Social Research, 41(2), 155-177.

Cho, C. H., Guidry, R. P., Hageman, A. M., \& Patten, D. M. (2012). Do actions speak louder than words? An empirical investigation of corporate environmental reputation. Accounting, Organizations and Society, 37(1), 14-25.

Cho, C. H., Laine, M., Roberts, R. W., \& Rodrigue, M. (2015). Organized hypocrisy, organizational façades, and sustainability reporting. Accounting, Organizations and Society, 40(1), 78-94.

Cooper, C., \& Senkl, D. (2016). An(other) truth: A feminist perspective on KPMG's true value. Sustainability Accounting, Management and Policy Journal, 7(4), 494-516.

Cooper, S. M., \& Owen, D. L. (2007). Corporate social reporting and stakeholder accountability: The missing link. Accounting, Organizations and Society, 32(7-8), 649-667.

Craig, R., \& Amernic, J. (2004). The deployment of accounting-related rhetoric in the prelude to a privatization. Accounting, Auditing and Accountability Journal, 17(1), 41-58.

Crane, A., \& Glozer, S. (2016). Researching corporate social responsibility communication: Themes, opportunities and challenges. Journal of Management Studies, 53(7), 1223-1252.

Desrosieres, A. (2001). How 'real' are statistics? Four possible attitudes. Social Research, 68, 339-355.

Dhaliwal, D. S., Radhakrishnan, S., Tsang, A., \& Yang, Y. G. (2012). Nonfinancial disclosure and analyst forecast accuracy: International evidence on corporate social responsibility disclosure. The Accounting Review, 87(3), 723-759.

Didier, E. (2018). Globalization of quantitative policing: Between management and statactivism. Annual Review of Sociology, 44, $515-534$.

Dillard, J., \& Vinnari, E. (2019). Critical dialogical accountability: From accounting-based accountability to accountability-based accounting. Critical Perspectives on Accounting, 62, 16-38.

Energiateollisuus. (2017). Suomalaisten Energia-asenteet 2017 [Finns' attitudes on energy production 2017]. Helsinki: Energiateollisuus.

Espeland, W. (2016). Reverse engineering and emotional attachments as mechanisms mediating the effects of quantification. Historical Social Research, 41(2), 280-304.

Espeland, W. N., \& Sauder, M. (2007). Rankings and reactivity: How public measures recreate social worlds. American Journal of Sociology, 113, 1-40.

Espeland, W. N., \& Sauder, M. (2016). Engines of anxiety. Academic rankings, reputation and accountability. New York: Russell Sage Foundation.

Espeland, W., \& Stevens, M. (1998). Commensuration as social process. Annual Review of Sociology, 24, 313-343.

Espeland, W., \& Stevens, M. (2008). A sociology of quantification. European Journal of Sociology/Archives Européennes de Sociologie, $X L I X(3), 401-436$.

Finnish Energy Industries. (2014). Energiavuosi 2014.

Folke, C., Österblom, H., Jouffray, J.-B., et al. (2019). Transnational corporations and the challenge of biosphere stewardship. Nature Ecology \& Evolution, 3, 1396-4103.

Gendron, Y. (2009). Discussion of 'The audit committee oversight process': Advocating openness in accounting research. Contemporary Accounting Research, 26(1), 123-134.

Gerdin, J., \& Englund, H. (2019). Contesting commensuration: Public response tactics to performance evaluation of academia. Accounting, Auditing \& Accountability Journal, 32(4), 1098-1116.

Gilles, M. (2016). Figures for what purposes? The issues at stake in the struggles to define and control the uses of statistics. In S. Bruno, F. Jany-Catrice, \& B. Touchelay (Eds.), The social sciences of quantification (pp. 149-160). Cham: Springer.

Hakkila, P. (2006). Factors driving the development of forest energy in Finland. Biomass and Bioenergy, 30, 281-288. 
Hooks, J., \& van Staden, C. J. (2011). Evaluating environmental disclosures: The relationship between quality and extent measures. British Accounting Review, 43, 200-213.

Kadous, K., Koonce, L., \& Towry, K. L. (2005). Quantification and persuasion in managerial judgement. Contemporary Accounting Research, 22(3), 643-686.

Kaspersen, M., \& Johansen, T. R. (2016). Changing social and environmental reporting systems. Journal of Business Ethics, 135, 731-749.

Laine, M., Järvinen, J., Hyvönen, T., \& Kantola, H. (2017). Ambiguity of financial environmental information: A case study of a Finnish energy company. Accounting, Auditing \& Accountability Journal, 30(3), 593-619.

Laine, M., Scobie, M., Sorola, M., \& Tregidga, H. (2020). Special issue editorial: Social and environmental account/ability 2020 and beyond. Social and Environmental Accountability Journal, $40(1), 1-23$.

Lempinen, H. (2013). "Arvalla heitetty? Tiede ja sen kyseenalaistaminen turve-energian markkinoinnissa. Tieteessä tapahtuu, 31(5), $35-38$.

Mau, S. (2019). The metric society. On the role of quantification and the social. Cambridge: Polity Press.

Mehrpoya, A., \& Samiolo, R. (2016). Performance measurement in global governance: Ranking and the politics of variability. Accounting, Organizations and Society, 55, 12-31.

Mennicken, A., \& Espeland, W. (2019). What's new with numbers? Sociological approaches to the study of quantification. Annual Review of Sociology, 45, 223-245.

Merry, S. E. (2016). The seductions of quantification. Measuring human rights gender violence and human trafficking. Chicago: University of Chicago Press.

Michelon, G., Pilonato, S., Ricceri, F., \& Roberts, R. W. (2016). Behind camouflaging: Traditional and innovative theoretical perspectives in social and environmental accounting research. Sustainability Accounting, Management and Policy Journal, 7(1), 2-25.

Miller, P., \& O'Leary, T. (1993). Accounting expertise and the politics of the product: Economic citizenship and modes of corporate governance. Accounting, Organizations and Society, 18(2-3), 187-206.

Miller, P., \& O’Leary, T. (1994). Accounting, "economic citizenship" and the spatial reordering of manufacture. Accounting, Organizations and Society, 19(1), 15-43.

Miller, P., \& O’Leary, T. (2007). Mediating instruments and making markets: Capital budgeting, science and the economy. Accounting, Organizations and Society, 32(7-8), 701-734.

O’Dwyer, B., \& Unerman, J. (2016). Fostering rigour in accounting for social sustainability. Accounting, Organizations and Society, $49,32-40$.

Peterson, B. (2014). The peat monster. Foreign Policy, October 2014. Retrieved November 20, 2014, from https://www.foreignpolicy. com/articles/2014/10/10/finland_environment_climate_chang e_peat_vapo_green_koijarvi_fishing_biodiversity.
Porter, T. M. (1992). Quantification and the accounting ideal in science. Social Studies of Science, 22(4), 633-651.

Porter, T. M. (1995). Trust in numbers. Princeton, NJ: Princeton University Press.

Potter, B. N. (2005). Accounting as a social and institutional practice: Perspectives to enrich our understanding of accounting change. ABACUS, 41(3), 265-289.

Power, M. (2004). Counting, control and calculation: Reflections on measuring and management. Human Relations, 57(6), 765-783.

Rose, N., \& Miller, P. (1992). Political power beyond the state: Problematics of government. The British Journal of Sociology, 43(2), 173-205.

Sauder, M., \& Espeland, W. N. (2009). The discipline of rankings: Tight coupling and organizational change. American Sociological Review, 74, 63-82.

Saxton, G. D., Gomez, L., Ngoh, Z., Lin, Y.-P., \& Dietrich, S. (2019). Do CSR messages resonate? Examining public reactions to firms' CSR efforts on social media. Journal of Business Ethics, 155, 359-377.

Schilstra, A. J. (2001). How sustainable is the use of peat for commercial energy production? Ecological Economics, 39, 285-293.

Syrjämäki, E. (2013). Mikä on oikeaa tietoa? Turvetuotannon diskurssit paikallisen tiedon näkökulmasta Saarijärven reitillä. Master's Thesis, University of Jyväskylä.

The Finnish Association for Nature Conservation [FANC]. (2014). Suuri suomalainen päästöhuijaus [The great Finnish discharge hoax]. Presentation, 4(4), 2014.

The Finnish Association for Nature Conservation [FANC]. (2012). Turpeenkaivuun vesistöongelmat [Problems peat mining causes to watersheds].

Tinker, T., \& Neimark, M. (1987). The role of annual reports in gender and class contradictions at General Motors: 1917-1976. Accounting, Organisations and Society, 12(1), 71-88.

Tuohy, A., Bazilian, M., Doherty, R., Gallachóir, B. Ó., \& O’Malley, M., (2009). Burning peat in Ireland: An electricity market dispatch perspective. Energy Policy, 37(8), 3035-3042.

Vaivio, J. (1999). Examining "the quantified customer". Accounting, Organizations and Society, 24(8), 689-715.

Vesty, G., Telgenkamp, A., \& Roscoe, P. (2015). Creating numbers: Carbon and capital investment. Accounting, Auditing \& Accountability Journal, 28, 302-324.

Vollmer, H. (2003). Bookkeeping, accounting, calculative practice: The sociological suspense of calculation. Critical Perspectives on Accounting, 14, 353-381.

Wiseman, J. (1982). An evaluation of environmental disclosures made in corporate annual reports. Accounting, Organizations and Society, 17(1), 53-63.

Publisher's Note Springer Nature remains neutral with regard to jurisdictional claims in published maps and institutional affiliations. 